\title{
DISSEMINATED CEREBRAL MICROBLEEDS IN SEPSIS ASSOCIATED REVERSIBLE POSTERIOR LEUKOENCEPHALOPATHY SYNDROME
}

\author{
Lale MEHDIKHANOVA*, Ethem Murat ARSAVA*, Rahşan GöÇMEN**, Kader KARLI OĞUZ**, \\ Mehmet Akif TOPÇUOGLU*
}

\begin{abstract}
*Hacettepe University Hospitals, Department of Neurology, Neurological Intensive Care Unit, Ankara, TURKEY **Hacettepe University Hospitals, Department of Radiology, Neuroradiology Section, Ankara, TURKEY.
\end{abstract}

\begin{abstract}
The report illustrates a case with innumerable disseminated cerebral microbleeds (CMBs) and posterior reversible encephalopathy syndrome (PRES) in a patient with hypertension and sepsis. Both sepsis and uncontrolled hypertension, if severe enough, might lead to PRES and CMBs via multiple mechanisms including endothelial dysfunction, vasoconstriction and coagulopathy. This case highlights their effect might be additive in milder cases.

Key Words: Posterior reversible leukoencephalopathy syndrome, PRES,cerebral microhemorrhage; cerebral microbleed; sepsis; SIRS.
\end{abstract}

\section{SEPSIS İLE İLIŞKILII GERI DÖNÜŞÜMLÜ POSTERIOR LÖKOENSEFALOPATI SENDROMUNDA YAYGIN}

\section{SEREBRAL MIKKROKANAMA: OLGU SUNUMU}

\section{ÖZET}

Süreç boyunca hipertansif seyreden bir sepsis olgusu geri dönüşümlü posterior lökoensefalopati sendromu (İngilizce akronimi "PRES") ve yaygın/sayısız serebral mikrokanama (SMK) ile komplike olmuştur. Eğer yeterince şiddetli ise hem sepsis hem de kontrolsüz hipertansiyon endotel disfonksiyonu, vazokontrüksiyon ve/veya infeksiyöz koagülopati mekanizmaları üzerinden PRES ve yaygın SMK gelişimine yol açabilir. Burada sunulan vaka iki antitenin birlikte bulunması halinde aditif etki yaparak, daha az hastalık şiddeti olan olgularda da gelișebileceğini işaret eder.

Anahtar Sözcükler: Posterior reversible lökoensefalopati sendromu, PRES, serebral mikrohemoraji, serebral mikrokanama, sepsis, SIRS.

\section{INTRODUCTION}

Cerebral hemorrhage occurs in approximately $15 \%$ of patients with posterior reversible leukoencephalopathy syndrome (PRES) (1). The frequency increases when magnetic resonance (MR) imaging sequences sensitive to occult hemorrhages such as gradient-recalled echo T2*[star] (2) and susceptibility-weighted imaging (SWI) are implemented. In a study using SWI, cerebral microbleeds (CMBs) were detected in 18 of 31 consecutive PRES cases while subarachnoid and intra-parenchymal hemorrhage was evident in 3 and 2 cases, respectively. The number of CMBs observed in this setting is 2.5-3.5 per patient on average, and are usually confined to the PRES related vasogenic edema regions. However, their number is not related to the extent of edematous and/or ischemic PRES lesions (3). We herein report "another" case of PRES-associated CMBs but with countless number of microbleeds and highly distinct distribution.

\footnotetext{
Corresponding author: Prof. Mehmet Akif Topçuoğlu MD. Hacettepe University Faculty of Medicine, Department of Neurology, 06100 Ankara, Turkey. Phone: +9003123061806 E-mail: matopcuoglu@yahoo.com Received: 17.06.2018 Accepted: 17.12.2018

This article should be cited as following: Mehdikhanova L, Arsava EM, Göçmen R, Karlı Oğuz K, Topçuoğlu MA. Disseminated cerebral microbleeds in sepsis associated reversible posterior leukoencephalopathy syndrome. Turkish Journal of Cerebrovascular Diseases 2019; 25 (1): 176-180. doi: 10.5505/tbdhd.2018.06978
} 
In this case, PRES developed after a poorly controlled hypertensive episode occurring in the setting of septicemia and systemic inflammatory response syndrome (SIRS). Very high number of CMBs was previously described in several patients with PRES, hypertensive encephalopathy and sepsis (4-6). Adding together, these cases give an opportunity to revisit and perhaps reformulate the pathophysiology underlying this specific PRES associated situation.

\section{CASE REPORT}

Eleven days prior to her referral to our center, this previously healthy 25-year-old female was admitted to another hospital, where an intravenous pyelogram (IVP) was performed for severe flank pain and suspicion of urolithiasis. Following IVP, her status was complicated with fever, headache, hypoxemia, tachycardia, vomiting and hemoptysis. She was then hospitalized, and clarithromycin and piperacillin/tazobactam treatments were empirically initiated with the presumptive diagnosis of acute onset urosepsis and/or pneumonia. A chest X-ray and transthoracic echocardiogram were found to be normal at that time.

On the next day, she was transferred to intensive care unit (ICU) because of worsening in her renal function and progressive mental deterioration, ultimately leading to coma. In ICU, she was intubated, and sedated with remifentanil. Until a sufficient sedation was achieved, she was continuously hypertensive in the range of 170-190 $\mathrm{mmHg}$ systolic and 100-110 $\mathrm{mmHg}$ diastolic, despite intravenous nitroglycerine therapy. Later on the same day, a consolidation in the right mid and inferior lung zones was noted. A fiberoptic bronchoscopy showed massive purulent bronchoalveolar secretions. Except for intervening thrombocytopenia (platelet counts dropping down to $46,000 / \mathrm{mm} 3$ ), her status remained stable for the next several days. She received six units of platelets for two days during this time. Renal ultrasound showed minimal pelvicaliceal dilatation. Corynebacterium spp was isolated in the bronchoalveolar lavage. Procalcitonin and leukocyte levels tended to decrease during this period.

Three days prior to admission to our hospital, she again became febrile and intravenous linezolide therapy was started. Two days later, she had repeated generalized tonic clonic seizures, which responded well to titrated intravenous midazolam infusion. A computed tomographic (CT) examination of the brain showed multifocal intracerebral hemorrhages; she was then transferred to our center. Of note, her mental status never recovered during the hospitalization period.

At the time of admission to our center, she was intubated, non-cooperative and quadriparetic with extensor response upon painful stimuli. There was marked disturbances in her liver and renal function tests. An emergency MR imaging showed symmetric T2 hyperintense lesions in the occipito-parietal white matter, corpus callosum and corona radiata with remarkable posterior dominance (Figure I a,b,c). The MR imaging findings were compatible with a diagnosis of PRES. However, SWI sequences displayed numerous microbleeds distributed in a widespread fashion throughout the brain, again predominantly in the posterior regions (Figure I d and II). Because of these extraordinary and atypical imaging characteristics, hemorrhagic encephalomyelitis including viral ones, atypical vasculitis and coagulation abnormalities were considered in the differential diagnosis. However, detailed work-up including cerebrospinal fluid analysis, tumor markers, and coagulation tests all were within normal limits. Her hemodynamic status was stabilized on the second hospitalization day; acute renal and liver dysfunction resolved afterwards. Her polymicrobial pneumonia was successfully treated with colistin, vancomycin and fluconazole. Tracheostomy and percutaneous endoscopic gastrostomy (PEG) were placed. Her neurological status gradually recovered. She started to vocalize and then verbally to communicate. However cortical blindness and quadriparesis persisted.

After three weeks of ICU stay, she was transferred to the neurology ward, where she stayed five more weeks. During this period, she continued to recover; tracheostomy was removed and her blindness and motor deficit gradually resolved. At the time of her transfer to a rehabilitation facility, she was able to mobilize independently. A follow-up MR imaging obtained 21 days later showed significant resolution of edematous PRES lesion in anterior regions, while in posterior regions, permanent tissue damage was documented (Figure Ie). 
SWI revealed persistence of previously observed CMBs without any evident decrease or increase in their number (Figure If). Six months after discharge, she had her PEG removed, was independent in her daily activities but had residual minimal weakness and cognitive impairment. A second follow-up MR imaging obtained 249 days later disclosed further regression of posterior PRES lesions along with constant number of CMBs (Figure Ig, Ih).

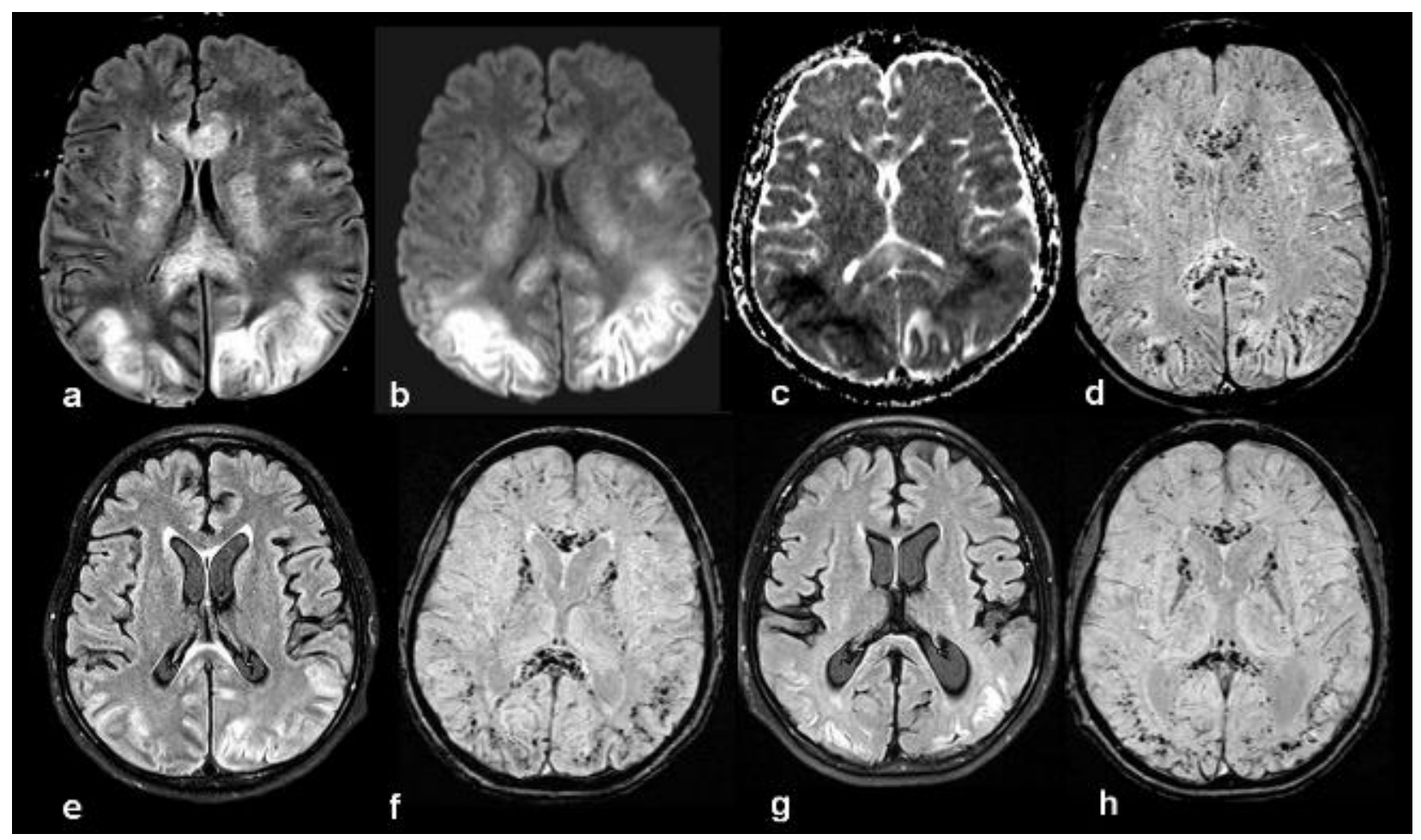

Figure I. Axial fluid attenuation inversion recovery(FLAIR) images show edematous lesions in the parieto-occipital region, corpus callosum, cingulate and basal ganglia bilaterally compatible with PRES (a). Lesions are bright on diffusion weighted imaging (b) with mixed findings on Apparent Diffusion Coefficient (ADC) maps (c). Clear diffusion restriction was discernible in the posterior areas. Widespread numerous CMBs are observed on Susceptibility Weighted Imaging (SWI) (d). CMB sare not necessarily located within PRES lesions and are present in the otherwise normal appearing regions. A follow-up MR imaging obtained 21 days later showed considerable regression of anterior and basal ganglia lesions (e). Of note, parieto-occipital lesions resulted in apparent tissue damage which was more evident on second follow-up MR imaging obtained 249 days later (g). SWI follow-up shows stable number of CMBs with no apparent new lesions (f,h). The permanence and stability of CMBs serves as a marker of single episode of hypertensive sepsis and implies fixed sequelae of this disorder.

\section{DISCUSSION}

We herein present a case of atypical hemorrhagic PRES syndrome occurring in the setting of hypertensive sepsis. CMB number and distribution were quite remarkable in this case, which was repeatedly studied with modern multimodal MR imaging modalities such as SWI, diffusion-weighted imaging (DWI) and apparent diffusion coefficient (ADC) mapping.

PRES is often associated with hypertension. Not uncommonly, punctate hemorrhages can be observed in hypertension-associated PRES. Their occurrence has been linked to abrupt and uncompensated increase in blood pressure to very high levels, similar to cases of hypertensive encephalopathy, where petechial hemorrhages together with fibrinoid necrosis, thrombosis of cerebral arterioles and microinfarctions comprise the well-known neuropathologic features. When blood pressure increases beyond very high values such as the range of $250 \mathrm{mmHg}$ systolic, microcirculatory changes including increased permeability of cerebral vasculature and bloodbrain barrier break-down develop and contribute, in addition to vasoconstriction, to formation of 


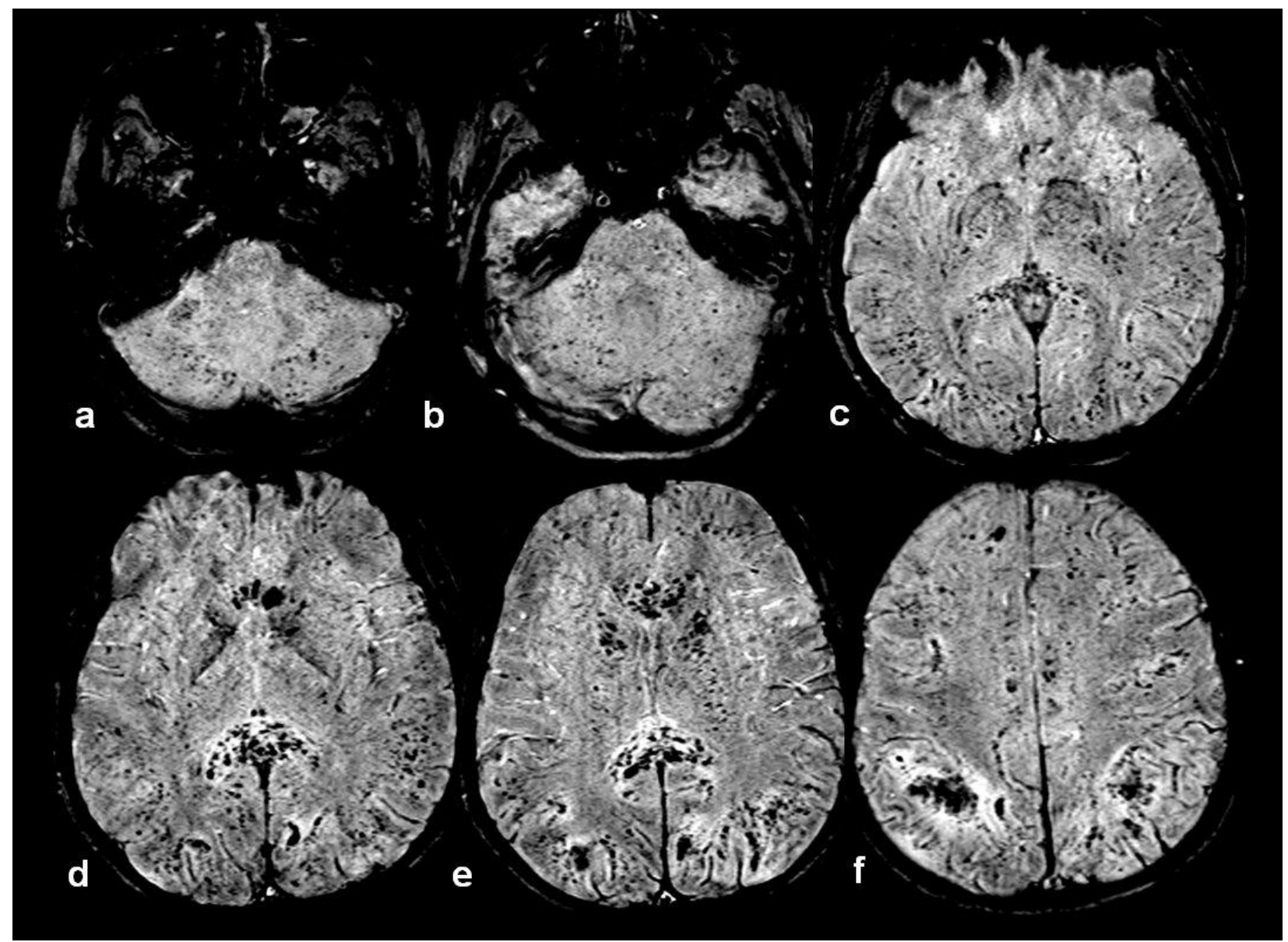

Figure II. Susceptibility Weighted Imaging (SWI) shows multiple wide spread and innumerable punctate foci of CMBs that are not apparent on any other sequences. Conglomerate formation is noted in some regions. Some of them are located in the edematous a reas, while others are not.

both PRES and petechial hemorrhages. As a result, CMBs are usually seen in such subjects with significantly higher blood pressure levels. Although hypertension related microhemorrhages are usually seen in basal ganglia, deep cerebral white matter and brainstem, additional or intervening factors affecting microvascular permeability or bleeding tendency might alter the load and distribution of CMBs in the setting of hypertension. This might explain the presence of high number of CMBs and their relatively atypical distribution such as corpus callosum and subcortical white matter (Figure II), observed in our case where relatively moderate elevations in blood pressure levels were accompanied by sepsis and thrombocytopenia. It is well known that sepsis results in disturbed microcirculatory reactivity, increased vascular permeability, inflammation related vascular changes, acquired coagulopathy, septic thrombocytopenia, and disseminated intravascular coagulopathy (7). Moreover, sepsis induced endothelial dysfunction can result in PRES itself. Indeed, endothelial dysfunction, rather than hypertension, is responsible for much of the pathogenesis of PRES observed in patients receiving immunosuppressive and antineoplastic medications. Therefore, it is not unexpected to observe both PRES and CMBs during the course of sepsis. In accordance, several reports have described septic cases with multiple CMBs without PRES4; PRES without CMBs (8-10) and PRES plus CMBs. However, the occurrence and characteristics of hemorrhagic lesions were not different in patients with PRES associated with isolated infection, sepsis, or shock, when compared to cases with PRES associated with other major clinical settings (11). These findings suggest that the key player in the formation of 
hemorrhagic lesions is the presence of hypertension.

In the case herein discussed, hemorrhagic leukoencephalopathy and PRES associated with cerebral amyloid angiopathy could also be considered in the list of differential diagnosis. However, the distribution and time course of lesions, together with the clinical presentation, excluded these possibilities. Similarly, infective endocarditis was properly excluded. Furthermore, except for the low platelet counts, other hemostatic variables including partial thromboplastin time, prothrombin time, D-dimer and fibrinogen were always within normal limits. In conclusion, an extraordinary MR imaging appearance in the setting of PRES has developed after a single episode of sepsis and undertreated hypertension in this case. No new lesions were detected during follow-up. As expected, edematous lesions resolved leaving some atrophy, while CMBs remained stable. Despite an initial massive lesion load, considerable clinical improvement was observed, which highlights the importance of supportive treatment in patients with PRES and sepsis.

\section{REFERENCES}

1. Hefzy HM, Bartynski WS, Boardman JF, Lacomis D. Hemorrhage in posterior reversible encephalopathy syndrome: imaging and clinical features. AJNR Am J Neuroradiol 2009; 30(7): 1371-1379.

2. Voetsch B, Tarlov N, Nguyen TN, et al. Asymmetric posterior reversible encephalopathy syndrome complicating hemodynamic augmentation for subarachnoid hemorrhage-associated cerebral vasospasm. Neurocrit Care 2011; 15(3): 542-546.

3. McKinney AM, Sarikaya B, Gustafson C, Truwit CL. Detection of microhemorrhage in posterior reversible encephalopathy syndrome using susceptibility-weighted imaging. AJNR Am J Neuroradiol 2012; 33(5): 896-903.

4. Correa DG, Cruz Junior LC, Bahia PR, Gasparetto EL. Intracerebral microbleeds in sepsis: susceptibilityweighted MR imaging findings. Arq Neuropsiquiatr 2012; 70(11): 903-904.

5. Kawai H, Nakamura H, Sanada M, Kitahara S, Maeda K. Microhemorrhages in a patient with reversible posterior leukoencephalopathy syndrome. Neurology 2006; 67(9): 1712.

6. Weingarten K, Barbut D, Filippi C, Zimmerman RD. Acute hypertensive encephalopathy: findings on spin-echo and gradient-echo MR imaging. American journal of roentgenology 1994; 162(3): 665-670.

7. Giraldo EA, Fugate JE, Rabinstein AA, Lanzino G, Wijdicks EF. Posterior reversible encephalopathy syndrome associated with hemodynamic augmentation in aneurysmal subarachnoid hemorrhage. Neurocrit Care 2011; 14(3): 427-432.

8. Fugate JE, Claassen DO, Cloft HJ, Kallmes DF, Kozak OS, Rabinstein AA. Posterior reversible encephalopathy syndrome: associated clinical and radiologic findings. Mayo Clin Proc 2010; 85(5): 427-432.

9. Schwenk J, Gosztonyi G. Purpura cerebri in gram-negative septicaemia. A histological and immunohistochemical study. Histology and histopathology 1987; 2(1): 57-66.

10. Romem A, Galante 0 , Shelef I, Almog Y. Posterior reversible encephalopathy syndrome complicating septic shock. Isr Med Assoc J 2011; 13(12): 776-778.

11. Bartynski WS, Boardman JF, Zeigler ZR, Shadduck RK, Lister J. Posterior reversible encephalopathy syndrome in infection, sepsis, and shock. AJNR Am J Neuroradiol 2006; 27(10): 2179-2190. 